\title{
Estimating Quarterly GDP for Nepal: An Applicationof Chow-Lin Procedure
}

\author{
Naveen Adhikari ${ }^{12}$ \\ Tulasi Nepal ${ }^{13}$
}

\begin{abstract}
Nepal started producing annual national income estimates following an internationally accepted system of 'National Account Systems' since the late 1960s; and, accordingly, the annual GDP figures for Nepal are available for a longer period. However, the production and publication of quarterly GDP for public consumption have been both rare and occasional. This paper aims to bridge this gap by providing an estimate for quarterly GDP for the period of 1997/98Q1 to 2017/18Q4 following well established Chow-Lin procedure. The quarterly exports and government tax revenue are used to extrapolate the magnitude and movement of quarterly GDP. The results show a deterministic seasonal movement over the quarters. In particular, increased economic activities are observed in the second and fourth quarters while making a comparison on quarter to quarter basis. It is expected that this paper will partially fulfill the gap of unavailability of quarterly GDP figures in the public domain, and documents that the researcher may use suitable econometric exercise to obtain inter-temporal disaggregation of low-frequency data such as annual GDP into quarterly figures.
\end{abstract}

Key words: Quarterly GDP, Inter-temporal disaggregation, Chow-Lin procedure, Seasonality, Nepalese economy

\section{Introduction}

There has been a growing need and interest among researchers and policymakers on the production of high-frequency gross domestic product (GDP) data such as on a quarterly or monthly basis. While such information is often available for the government finance and balance of payment accounts; information on the real sector, particularly the national income estimate, is still limited due to large data requirements, institutional capacity, and huge resource requirements among others(Bloem et al., 2001). Accordingly, disaggregation of annual data series into quarterly or monthly series applying suitable time series econometric tools has been a common practice across the researchers and institutions.

The needs for quarterly estimates of real sector figures are well documented in the literature. EC (2013)asserts that quarterly national accounts (QNA) are crucial in assessing the short-run

\footnotetext{
${ }^{12}$ Mr. Adhikari is Assistant Professor at Central Department of Economics, Tribhuvan University. Email: n.adhikari@cedecontu.edu.np.

${ }^{13} \mathrm{Mr}$. Nepal (Corresponding author) is research fellow at Shodhashala-Center for Research and Policy Studies, Baluwatar, Kathmandu, Nepal. All queries should be addressed at trnepal30@gmail.com.
} 
movement of real series such as GDP and provide more reliable estimates for the forecasting. QNA helps to identify phases of the economic cycle; provides a timely diagnosis of changing the structure of the economy; helps for effective mentoring; and suggests the policies to be taken to stabilize short term target variables (ADB, 2015). This is also important from the researcher's point of view where they wish to examine the relationship between high-frequency data and the real sector of the economy (Sax \& Steiner, 2013). For example, the information on stock prices, government taxes and expenditure, exports, imports, prices are available on a daily, weekly, monthly, or quarterly basis. However, the lack of availability of high-frequency data in the real sector, it limits and complicates the estimation procedure to examine the short relationship between these variables. Further, long quarterly GDP is desirable for econometric analysis due to its satisfying statistical properties (Abeysinghe \& Lee, 1998; Sax \& Steiner, 2013).

Nepal started producing the national account estimates following the internationally comparable system of national accounts (SNA) in the late 1960s. The annual GDP series for Nepal are available from as early as 1964/65 (MoF, 2015). However, owing to methodological limitations due to severe data constraints, the annual GDP series from 1974 is more credible and internationally comparable (NPC, 1975). Despite such a long history of producing annual series, the production of quarterly GDP remains rather occasional. For the first time, the Central Bureau of Statistics (CBS), Nepal produced quarterly GDP in 2015, which reported the quarterly estimated figures for 2005Q1 to 2012Q2 (ADB, 2015; CBS, 2015). The estimates only included the quarterly growth rate of GDP. However, CBS has stopped disseminating it to the public in recent years.

Therefore, the motivation to produce this paper is twofold. First, the paper provides an estimate for quarterly gross domestic product (QGDP) for the period of 1998Q1-2018Q4 using the well-established econometric procedure. This essentially complements the figures produced by CBS stretching over a relatively long period. This paper will further reflect the fact that the production of quarterly figures is possible using a suitable methodology. Second, this aims to discuss the features of the quarterly data such as seasonality and structural breaks which would be helpful in understanding the short-run movement of output in Nepal. It is further expected that researchers may use the data produced in this paper to integrate the high-frequency data such as tax, trade, or stock price index with the real sector to examine the relationship between these variables.

\section{A Brief Survey of Disaggregation Techniques}

In need of high frequency data, Friedman (1962) provided an idea to estimate the unobserved low frequency data from the observed high frequency series. However, a mere application of Friedman idea could create an accounting problem. For example, the estimated quarterly GDP must average the observed annual series. Later, Lisman and Sandee (1964), and Cohen, Muller and Padberg (1971) corrected those accounting problem but they failed to consider the explaining variables that would potentially reflects the movement of GDP. However, the proliferation of literature begun with a development of methodology by Chow and Lin (1971) and Denton (1971) as they addressed both temporal restricts on unobserved series and consider the explaining or indicator variables for extrapolations. Apparently, there have been several extensions and modifications to these approaches (Fernandez, 1981; Litterman, 1983; and Chan, 1993). 
Denton (1971) primarily relies on the movement preservation, and generates a series compatible with the high-frequency indicator series. While this method does not attempt to check the relationship between indicator variables and GDP statistically, the common practice is to use a high frequency indicator that has potential to explain the movement in GDP; and covert the annual GDP into high frequency series based on the movement of the indicator variable (Sax \&Steiner, 2013). This method has satisfying accounting properties required in combing low frequency and high frequency data such as benchmarking and has a distinct advantage of disaggregating low-frequency data into high frequency even in the absence indicator series.

On the other hand, Chow-Lin (1971), Fernandez (1981), and Litterman (1983) developed econometric models where one can use one or several indicator variables and do a regression on the low-frequency series. However, the methods of Chow-Lin, Fernandez, and Litterman differ in terms of co-integrating nature indicators and low frequencies series. Chow-Lin procedure does require stationary and co-integrated series whereas Fernandez and Litterman deal with non-co-integrated series.

As the study found the use of both types of methods in the literature, the selection of methods in a particular context is always challenging. Moreover, the study does not have compelling evidence to choose one model over the others. However, application of Chow-Lin procedure has been common across the empirical investigations. For example, Abeysinghe and Lee (1998) have disaggregated annual GDP to quarterly GDP by sectors for Malaysia and generated superior results. They separately interpolated quarterly GDP for the industry, agriculture, and service sector and used agricultural production index and industrial production index as related variables for industry and agriculture, respectively. Khai (2009) obtained a fairly good quality of interpolated high-frequency GDP series using the Chow-Lin method for Vietnam. The author choses nominal interest rate and real money supply, based on the theory of the LM curve, as interpolators to estimate quarterly real GDP for 1992 to 2007 and got fairly good quarterly estimates.

Similarly, Karan (2013) used the models of both Chow-Lin and Fernandez to disaggregate GDP in Fiji and found that method of Fernandez to be more suitable for Fiji. Using different econometric techniques, including the Chow-Lin framework, Rashid and Jehan (2013) converted annual GDP, investment spending, and government expenditure data into quarterly for Pakistan for the period 1971-2010. To disaggregate annual data, they used the quarterly consumer price index (CPI) and industrial production index (IPI) as the indicator variables.

The literature suggests that the disaggregation of annual GDP into quarterly can be performed using different econometric techniques. In the case of having integrated related series, the Chow-Lin method has proven as a robust method of disaggregating higher frequency data into the lower. Therefore, this study tries to use the Chow-Lin approach confirming that our variables are related and co-integrated. This paper aims to fulfill the gap in view of unavailability of quarterly GDP publicly in Nepal for relatively longer period.

\section{Methodology}

In this section, the study first discusses the Chow-Lin procedure of disaggregating highfrequency data into low-frequency series. This is followed by a discussion of choosing the indicator variables, data sources, and a brief overview of time series econometrics employed in the paper. 


\section{Chow-Lin procedure of Disaggregation}

Chow and Lin (1971) developed a static multivariate regression model to disaggregate low frequency to high-frequency time series. In their original work, they presented a model to convert quarterly observed data into monthly data. However, this model can easily be used to disaggregate annual data to quarterly estimate from the observed quarterly data of the indicator variable. This approach considers that GDP data are available annually over $\mathrm{n}$ years. Then, let $\mathrm{y}_{\mathrm{q}}$ be a $(4 n \times 1)$ vector of quarterly GDP figures to be estimated. There is a matrix $C(n \times 4 n)$ that converts $4 \mathrm{n}$ quarterly observations into annual observations. This matrix can be written as:

$$
\mathrm{C}=\left[\begin{array}{llllllllllllllll}
1 & 1 & 1 & 1 & 0 & 0 & 0 & 0 & . & . & . & . & 0 & 0 & 0 & 0 \\
0 & 0 & 0 & 0 & 1 & 1 & 1 & 1 & . & . & . & . & . & . & . & . \\
. & . & . & . & . & . & . & . & . & . & . & . & 0 & 0 & 0 & 0 \\
0 & 0 & 0 & 0 & . & . & . & . & 0 & 0 & 0 & 0 & 1 & 1 & 1 & 1
\end{array}\right] \ldots \ldots . . .(1)
$$

In order to convert the annual to quarterly or vice-versa, first requirement is to establish a relationship between variable of interest (for example, GDP in this case) along with indicator variables called the predictor. This can be illustrated as:

$$
\boldsymbol{Y}_{q}=\boldsymbol{X}_{q} \boldsymbol{\beta}+\boldsymbol{u}_{q}
$$

Where, $\mathrm{X}_{\mathrm{q}}$ is a (4nxk) matrix of $\mathrm{k}$ predictor variables observed quarterly and $\mathrm{u}_{\mathrm{q}}$ is a ( $\left.4 n \times l\right)$ random vector with zero mean and covariance matrix $V(4 n \times 4 n)$. Our interest is to estimate quarterly GDP (yq) from available annual GDP series (Ya). They can be linked with the help of converter matrix (Equation 2) as:

$$
\boldsymbol{Y}_{a}=C y_{q}=C X_{q} \beta+C u_{q}=X a \beta+u_{a .}
$$

In order to get best linear estimator of $y_{\varphi}$, according to Chow-Lin method, we first need to apply 'Generalized Least Square (GLS)' method to equation (3). By doing so, the study obtains $\widehat{\boldsymbol{\beta}}=\left(\boldsymbol{X}_{a}{ }_{a} \boldsymbol{V}_{a}^{-1} \boldsymbol{X}_{\boldsymbol{a}}\right)^{-\boldsymbol{t}}\left(\boldsymbol{X}_{\boldsymbol{a}} \boldsymbol{V}^{-1}{ }_{\boldsymbol{a}} \boldsymbol{y}_{\boldsymbol{l}}\right)$, where $\boldsymbol{V}_{\boldsymbol{a}}=\left(\boldsymbol{C} \boldsymbol{V}_{q} \boldsymbol{C}\right)$. Thus, the Chow- Lin best linear unbiased predictor of $\mathrm{y}_{\mathrm{q}}$ is derived from:

$$
\widehat{\boldsymbol{y}}_{q}=\mathrm{X}_{\mathrm{q}} \widehat{\boldsymbol{\beta}}+V_{q} C^{\prime}\left(C V_{q} C^{\prime}\right)^{-1} \widehat{\boldsymbol{u}}_{\mathrm{a}}
$$

Where $\hat{u}_{a}=y_{a}-X_{a} \widehat{\beta}$ is the GLS residuals of the equation (3). As proposed in the Chow-Lin method,the first term on the RHS of equation (4) gives the predictedy ${ }_{q}$ based on observed quarterly $\mathrm{X}_{\mathrm{q}}$ and estimated $\beta$ from annual totals, whereas the second term does allocate annual residuals $\widehat{u}_{a}$ to the four quarters of the year such that the annual total of the disaggregated values equal the observed value $y_{a .}$

The difficulty of the Chow-Lin procedure is that $\mathrm{V}_{\mathrm{q}}$ is unknown. Chow and Lin (1971) have considered these two cases: (a) $\mathbf{V}^{2}=\sigma^{2} I_{4 n}$ and (b) $u_{t}=\rho u_{t-1}+e_{t}$ where $\mathbf{e}_{t}$ is white noise and $|\rho|<1$. Under assumption, (a) $\widehat{\boldsymbol{\beta}}$ reduces to the OLS estimator $\left(\boldsymbol{X}_{a}^{\prime} \boldsymbol{X}_{a}\right)^{-1}\left(\boldsymbol{X}_{a}^{\prime} \boldsymbol{y}_{a}\right)$, and the second term on the RHS of equation (4) amounts to allocating one quarter of the annual GLS residual to each quarter of the year. For the second case, the variance and covariance matrix $\mathrm{V}_{\mathrm{q}}$ takes form given in expression (5).

$$
V_{q}=\sigma_{e}^{2}\left[\begin{array}{ccccccc}
1 & \rho & \rho 2 & . & . & . & \rho 4 n-1 \\
\rho & 1 & \rho & . & . & . & \rho 4 n-2 \\
\cdot & . & . & . & . & \cdot & . \\
\rho 4 n-1 & . & . & . & . & . & 1
\end{array}\right]
$$


There are several ways that estimate the autoregressive parameter $\rho$ as suggested by ChowLin. However, there may not be a convenient way of estimating $\rho$. The study followed the method suggested by Chow-Lin procedure for estimating the $\rho$. This suggests for solving the polynomial equation given in equation (6).

$$
\rho^{7}+2 \rho^{6}+3 \rho^{5}+4 \rho^{4}+\left(3-2 \widehat{\rho_{a}}\right) \rho^{3}+\left(2-4 \widehat{\rho}_{a}\right) \rho^{2}+\left(1-6 \widehat{\rho}_{a}\right) \rho-4 \widehat{\rho}_{a}=0 \ldots \ldots(6)
$$

In view of computational complications manually, the study uses the 'Tempdisagg' package available in R for temporal disaggregation of GDP as discussed above.

\section{Choice of Indicator Variables and Data Source}

To obtain quality disaggregated quarterly GDP, the related variables (predictors) should reflect the pattern of economic activities of a particular country. The priori assumption is that most of the economic activities in Nepal took place in the second and fourth quarter compared to other quarters in a fiscal year. The major agriculture harvests such as paddy and maize takes place in the second quarter. Likewise, major public sector activities such as construction, government settlement of funds for payments, and private sector loan settlements are undertaken in the fourth quarter. Therefore, it is imperative that our indicator variables reflect this pattern of economic activities.

Given this presumed nature of quarterly GDP in Nepal, data availability on quarterly agricultural output or construction indices that reflects the quarterly movement of the GDP over a continuous time period is rare. Further, the Chow-Lin procedure requires that chosen indicator variables are co-integrated with GDP to get stationary of the error term, as indicated in the equation (2). Therefore, considering both of the requirements, the study used the quarterly figures of 'Government Tax Revenue' and 'Merchandise Exports' as indicator variables for the study. The 'Government Tax Revenue' includes the total amount of tax that the government of Nepal receives from its taxpayers in a specific fiscal year, as reported in the Nepal Rastra Bank (NRB) treasury. Likewise, merchandise exports include the exports of goods as defined in the Balance of Payment (BoP)Accounts published byNRB.

The study assumes that government tax may capture the pattern of economic activities between the quarters as increased economic activities induced increased monetary transactions thereby contributing to tax collection. While agricultural productions are exempted from tax, their forward linkages such as transactions with the manufacturing or service sector might have implications for tax collection. Further, exports basket of Nepal consist of primary agricultural commodities and the pattern of exports should also reveal the movement of economic activities between the quarters.

The data source includes 'National Income Estimates' produced by CBS for GDP, Government Finance Statistics, Economic Bulletin and Indicators published by NRB for tax and export-related figures. Since these figures were not available in a single publication, various issues of these publications were consulted to get figures for the study period. Considering the data availability of selected variables, this study covers a period of 21 years from FY 1997/98 to $2017 / 18$. 


\section{Converting Current Price GDP into a Constant Price Series}

The study derives the estimates based on the nominal figures of variables used in the study. Converting the GDP at current price series to a constant price series is essential for a better understanding of the movement of real GDP between the quarters. Given that no GDP deflator series is available on a quarterly basis, the adjustment is done taking the quarterly 'Wholesale Price Index (WPI)' reported by NRB. For this, the annual GDP deflator is disaggregated as per the movement of the WPI between the quarters. For instance, if the WPI increases by 4 percent from Q1 to Q2 of a particular year, we increase the annual GDP deflator of the same year by 4 percent to get Q2's deflator.

\section{Application of Time Series Econometric tools}

\section{Unit Root test}

Augmented Dickey-Fuller (ADF) test is applied to examine the presence of a unit root in the data. The application of ADF in checking the stationary properties of the time series data is well documented in the literature (Enders, 2008; Gujrati, 2009). The ADF test for a series say Yt for the presence of unit root can be expressed as:

$$
\Delta Y_{t}=\beta_{1}+\beta_{2} t+\delta Y_{t-1}+\sum_{i}^{m} \alpha_{i} \Delta Y_{t-i}+\varepsilon_{t} \ldots \ldots . .(7)
$$

Where, $\varepsilon t$ a pure white noise error term, and $Y_{t}$ is a variable used in this study such as GDP, tax, and exports. The series test for the presence of unit root under the null hypothesis that $\delta=0$. Accordingly, the series $Y_{t}$ is said to be stationary or free from the presence of unit root if the null hypothesis is rejected. The procedure is repeated for the difference of different orders to examine the presence of unit roots in the series. The study performs the test considering the inclusion of intercept only, and both trend and intercept while the length of lag is determined based on the Akaike Information Criteria (AIC).

\section{Engle-Granger Co-Integration}

The study finds that all variables under study are integrated of order one i.e. I(1). That means, the series becomes stationary at the first difference. Accordingly, the study performs the Engle-Granger two step procedures to check whether variables are co-integrated (Engel \& Granger, 1991; Enders, 2008). In the first step, an OLS technique is applied to derive an estimate of relationship considering GDP as dependent variable; and tax and exports as independent variables. The equation therefore takes the form of:

$$
G D P_{t}=\alpha+\beta_{1} T_{A X}+\beta_{2} E X X O R T_{t}+u_{t} \ldots \ldots \ldots \ldots \ldots \text { (8) }
$$

In second step, $\mathrm{ADF}$ test is performed for checking presence of unit root in the estimated residual obtained from equation (2). If the series are integrated of order one, then the residuals should follow stationary process as the linear combination of series must cancels the nonstationary movements. Since the value of $\beta$ is not know in prirori, the residuals are estimated using the predicted value of $\mathrm{GDP}_{t}$

$$
\widehat{\boldsymbol{u}}_{t}=\widehat{\boldsymbol{G D P}}_{t}-\widehat{\alpha}-{\widehat{\beta_{1}}} T_{A X}-{\widehat{\beta_{2}}} \text { XXPORT }
$$

The estimated residual is checked for the presence of unit-root following ADF test as discussed above. 


\section{Testing Seasonality}

Since the objective of the paper is to know the nature of the estimated quarterly GDP, The study checked for the presence of seasonality. As evident in literature and a priori assumptions about the trend as well as movement of GDP across the quarters in Nepal, the study check for the presence of deterministic seasonality owing to particular movement of estimated figures over the quarters. In a simpler framework, this suggests regressing the quarterly GDP with quarterly dummies (Hylleberg, 1992; Chatterjee \& Hadi, 2015). This takes the form of following regression,

$$
G D P_{q t}=\beta_{0} t+\beta_{1} q_{1}+\beta_{2} q_{2}+\beta_{3} q_{3}+\beta_{4} q_{4}+e_{t} \ldots \ldots \ldots \ldots(10)
$$

Where, $\mathrm{GDP}_{\mathrm{qt}}$ is the quarterly GDP, $\mathrm{t}$ is the time capturing trend, qi $(\mathrm{I}=1,2,3,4)$ are the seasonal dummies for respective quarter and $e_{t}$ is the error term. Here, if F-ratio and estimated $\beta_{i}$ are statistically significant, we can infer the presence of seasonality in the series. In this model, we omit the constant term to avoid the dummy trap.

\section{Results and Discussion}

\section{Results of Stationary and Co-integration test}

The results of Augmented Dickey-Fuller (ADF) on examining the presence of unit root in the series are reported in Annex-1. Since the Chow-Lin procedure requires the variables under consideration to be co-integrated, it is necessary to examine the presence of unit root in both level and first difference form of the data. The results show that all the variables under considerations- annual GDP, tax, and exports - are non-stationary at their level form. The presence of unit root is consistent between the inclusion of trend only and trend with intercept in the ADF test. The study find, however, all the series are free from the unit root in their first difference forms implying that all series are integrated of order 1 i.e. $I(1)$. Further as per the requirement to apply the Chow-Lin procedure, the estimated residuals of equation (9) confirms for the existence of co-integrating relationship between the variables at 5 percent level of significance. Since these tests are a part of the statistical requirements to apply Chow-Lin procedure, we don't delve into explaining such properties in details.

\section{Regression Results to obtain quarterly data}

Table 1 reports the regression results of annual nominal GDP on the tax and exports as discussed in the methodology section. The overall fitness of the model seems reasonably well as depicted by the F-ratio. The F value is statistically significant at 1 percent. The R-square is high (0.84)- which is natural in the time series data- suggesting that 82 percent variation in the quarterly GDP is explained by the indicators tax and exports employed in the study. Further, the estimated coefficients for tax and exports are both positive and statistically significant at 1 percent and 5 percent respectively. In line with presumption that increased tax collections and exports reflect the increased economic activities, the positive sign of the estimated coefficient confirms the same. That means increase in tax or export is expected to contribute to increased economic activities during particular quarter. While positive exports -GDP relationship is well documented in literature, there are mixed evidence about role of tax in GDP. The general hypothesis is that tax may negatively affect the GDP if it goes beyond the particular threshold. 
Table 1: Regression Results of Chow-Lin Method (1997/98Q1- 2017/18Q4)

\begin{tabular}{|l|c|}
\hline \multicolumn{1}{|c|}{ Dependent Variable: Annual GDP } & Coefficients \\
\hline Constant & $11000.00((74710.00)$ \\
\hline Tax & $2.16^{* * *}(0.23)$ \\
\hline Exports & $3.72^{* *}(1.72)$ \\
\hline \multicolumn{2}{|c|}{ R-squared $=0.8452$, Adj. R-Square $=0.8289$, F-ratio $=1203.53, \mathrm{~N}=84$} \\
\hline
\end{tabular}

Standard errors in parentheses $* * * \mathrm{p}<0.01, * * \mathrm{p}<0.05, * \mathrm{p}<0.1$.

Source: Author's computation

The estimated QGDP figures derived from Table 1 are reported in Annex-2. Figure 1summarizes the trend of estimatedquartile GDP for the period of 1997/98Q1 to 2017/18Q4. The figure 1 shows the presence of trend and seasonal movements across the quarters. The increasing trend of quartile GDP seems obvious- as the annual GDP is increasing over the years. For example, it was around Rs.749,550 millionin 2016/17 and increased to Rs. 797,146 million in 2017/18 registering about 6.3 percent point increase in the GDP. It is, however, also important to note the seasonal movements between the quarters. A quarter to quarter movement suggests that second and fourth quarters have higher GDP compared to first and third quarter respectively.

Figure 1: Quarterly GDP 1998Q1-2018Q4 in level form (at constant price 2000/01)

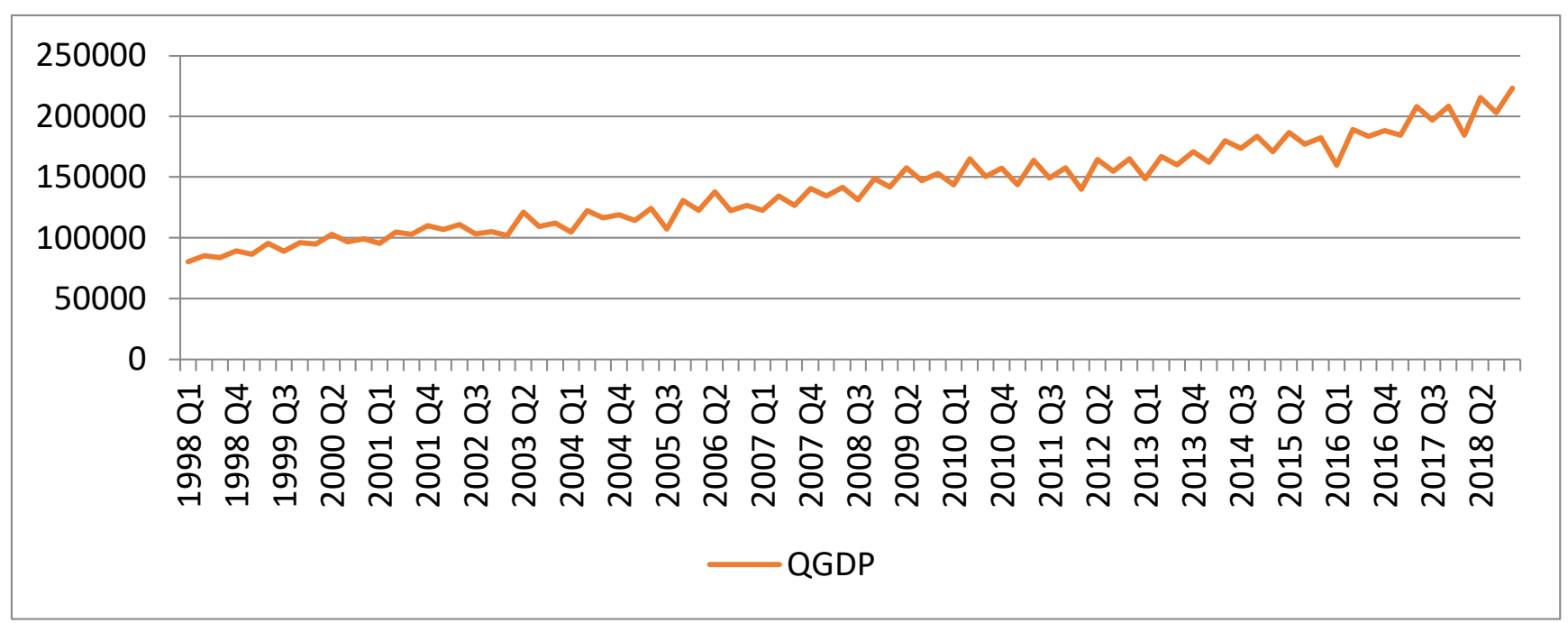

Source: Author's calculation (Appendix - 2)

To further look into the seasonal patterns of the estimated figures, the results shows a presence of seasonality in data assuming a deterministic trend as discussed in the methodology. The results show a strong presence of seasonality in the data. Both F-ratio and quarterly dummies were found significant (Table 2).

By controlling the trend, estimated figures show on an average that quarters 2 and 3 have a relatively higher value of GDP. On average, quarters 2 and 3 accounted for 87,046 and 83,727 million GDP respectively, while quarter one and quarter 3 have the GDP value of 72,609 and 76,414 respectively. 
Table 2: Presence of Seasonality in QGDP in Rs. Million: 2000/01 at Constant Price

\begin{tabular}{|c|c|}
\hline Dependent Variable (Quarterly GDP) & Coefficients \\
\hline Trend & $1,420^{* * *}(27.55)$ \\
\hline Q1 & $72,610^{* * *}(1,748)$ \\
\hline Q2 & $87,046^{* * *}(1,766)$ \\
\hline Q3 & $76,414^{* * * *}(1,784)$ \\
\hline Q4 & $83,728^{* * *}(1,803)$ \\
\hline R-Squared: 0.9983, Adj. R-squared: 0.9982, F-ratio=9390. $74(0.00), \quad \mathrm{N}=84$ \\
\hline
\end{tabular}

Standard errors in parentheses $* * * \mathrm{p}<0.01,{ }^{* *} \mathrm{p}<0.05,{ }^{*} \mathrm{p}<0.1$

Source: Author's computation based on Appendix - 2 data

For better illustration, the growth of quarterly GDP, including both seasonally adjusted and unadjusted series, is presented in Figure 2. It is, however, important to consider that disaggregation exercise rests on estimating GDP value on the level form. That means this exercise does not attempt to disaggregate the annual growth across the different quarters of the economy. Therefore, the growth presented in Figure 2 shows the quarter-to-quarter growth and accordingly warrants a careful interpretation. Nevertheless, it is found that Q2 and Q4 are often associated with a high growth rate compared to previous quarters. The increased economic activities in the second quarter might be because of several reasons. First, the second quarter consists of major crops harvesting time especially the paddy, which contributes about 7 percent to the GDPof nation.

Therefore, the year that has seen high agriculture growth is largely coming from the second quarter. Second, this quarter is just after the major festivals of Nepal. The domestic tax collections might have increased during this quarter following both major festivals and account closure of half-yearly business activities. Third, preparatory works such as procurement for public sector undertakings also get accelerated in the second quarter, which might reflect the increased public sector activities such as construction in this quarter. Likewise, a plausible explanation for increased GDP in the 4Q may be because of increased government capital expenditure in that quarter. It is well documented that the government spends about 50-60 percent of its capital expenditure in the last quarter. Further, payment settlements in both public and private sectors are done in the last quarter of the fiscal year. These accounting practices might have contributed to increased economic activities in the fourth quarter. 
Figure 2: Growth of Quarterly GDP in \% (Seasonally Adjusted and Unadjusted)

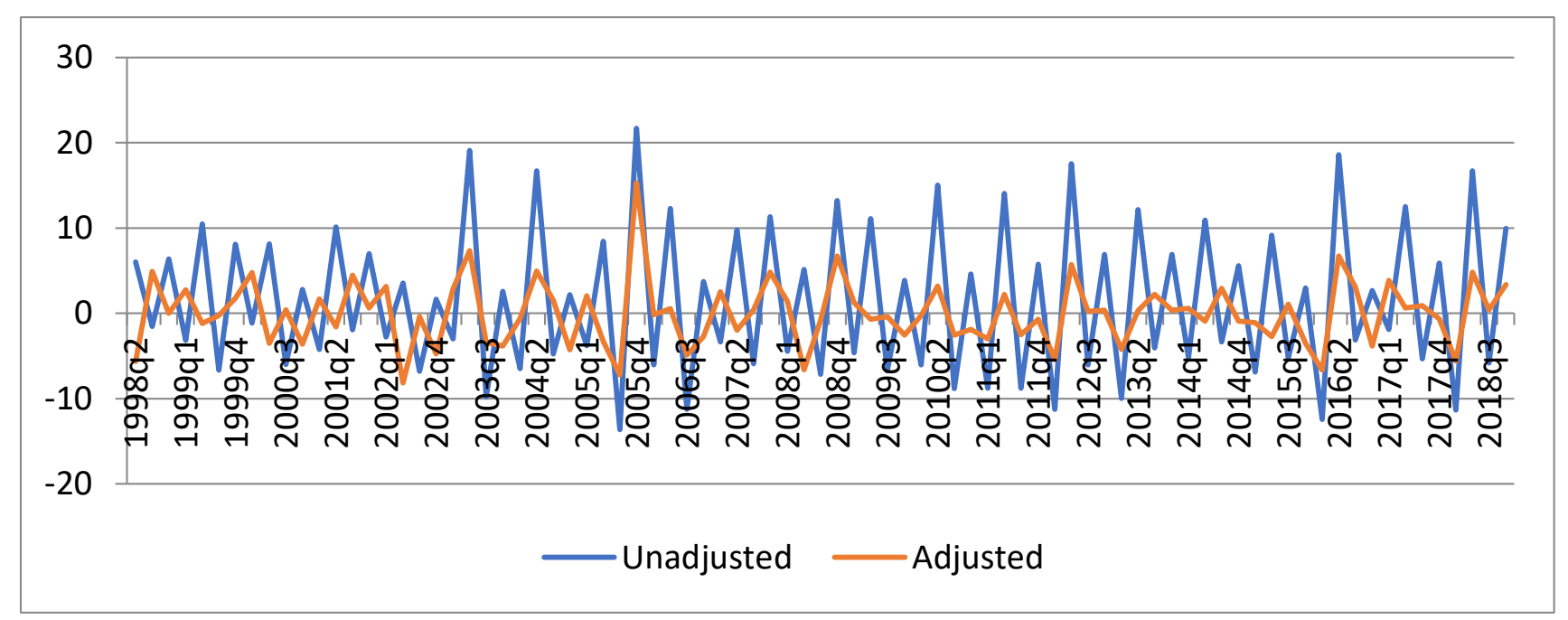

Source: Author's calculation (Appendix - 2)

\section{Conclusion}

The study applied temporal disaggregation methods as developed by Chow-Lin (1971) for the period of 1997/98 q1-2018/19 Q4. The total tax amount that the federal government collects and the amount of total merchandise exports are taken as the predictors to convert the annual GDP into a Q1. As required by the Chow-Lin method, the test results confirm that the series under consideration are co-integrated. In absence of quarterly deflator series, the process is to first compute the quarterly GDP series in nominal form and later convert it into constant series in 2000/01 prices taking WPI.

The study found that the estimated quarterly GDP series have strong cyclical movements over the quarters. In particular, the results suggest that more GDP is produced in Q2 and Q4. It is anticipated that increased agriculture products, specifically the paddy, in the Q2, and increased government capital expenditure in the Q4 have contributed to increased economic activities in these respective quarters.

The motivation to produce this paper was to apply suitable econometric tools for getting quarterly GDP estimates for Nepal which are not readily available to the public. However, one may argue over the method and choice of indicator variables used in this paper. Therefore, it is required that such results are verified using an alternative methodology and in particular by choosing the better indicator series that better captures the movement of GDP over the quarters. This paper, as such, does not delve into checking the robustness of the results so obtained. It is, therefore, recommended to check sensitivity in results considering different approaches and indicator variables that have better explanatory power. The study leaves this as a scope for further research. 


\section{References}

Abeysinghe, T., \& Lee, C. (1998). Best linear unbiased disaggregation of annual GDP to quarterly figures: The case of Malaysia. Journal of Forecasting, 17(7), 527-537.

ADB (Asian Development Bank) (2015). Macroeconomic Update: Nepal, Kathmandu: Asian Development Bank, 3 (1).

Bloem, A. M., Dippelsman, R., Maehle, N. O., \& Mæhle, N. Ø. (2001). Quarterly national accounts manual: Concepts, data sources, and compilation. International Monetary Fund.

CBS (Central Bureau of Statistics) (2015). Quarterly GDP for Nepal: 2011-2014. Kathmandu: Central Bureau of Statistics, Government of Nepal.

Chan, W. S. (1993). Disaggregation of annual time-series data to quarterly figures: A comparative study. Journal of Forecasting, 12(8), 677-688.

Chatterjee, S.\&Hadi, A. S. (2015). Regression analysis by example.John Wiley \& Sons.

Chow, G. C., \& Lin, A. L. (1971).Best linear unbiased interpolation, distribution, and extrapolation of time series by related series. The Review of Economics and Statistics, 372-375.

Cohen, K. J., Müller, W., \& Padberg, M. W. (1971). Autoregressive approaches to disaggregation of time series data. Journal of the Royal Statistical Society: Series C (Applied Statistics), 20(2), 119-129.

Denton, F. T. (1971). Adjustment of monthly or quarterly series to annual totals: An approach based on quadratic minimization. Journal of the American Statistical Association, 66 (333), 99-102.

Enders, W. (2008). Applied econometric time series.John Wiley \& Sons.

Engle, R., \& Granger, C. (1991). Long-run economic relationships: Readings in cointegration. Oxford University Press.

EC (European Commission) (2013).Handbook on Quarterly National Accounts. Eurostat manuals and guidelines, Luxembourg: European Commission.

Fernandez, R. B. (1981). A methodological note on the estimation of time series. The Review of Economics and Statistics, 63(3), 471-476.

Friedman, M. (1962).The interpolation of time series by related series. Journal of the American Statistical Association, 57(300), 729-757.

Gujarati, D. N. (2009). Basic econometrics.Tata McGraw-Hill Education.

Hylleberg, S. (1992). Modelling seasonality. Oxford University Press.

Karan, A. (2013).Quarterly output indicator series for Fiji. Economic Group, Reserve Bank of Fiji, EGWP, 1.

Khai, V. T. (2012). Estimates of quarterly real GDP for Vietnam. Journal of the Faculty of Economics, Seikei University, Vol.43(1) 13-22.

Lisman, J. H. C., \&Sandee, J. (1964). Derivation of quarterly figures from annual data. Journal of the Royal Statistical Society: Series C (Applied Statistics), 13(2), 87-90.

Litterman, R. B. (1983). A random walk, Markov model for the distribution of time series. Journal of Business \& Economic Statistics, 1(2), 169-173. 
52 | The Economic Journal of Nepal (Issue No. 152)

MoF(Ministry of Finance) (2015).Economic Survey - 2072/73. Kathmandu: Ministry of Finance, Government of Nepal.

NPC (National Planning Commission) (1975). Fifth Periodic Plan: 1975-80. Kathmandu: National Planning Commission, Government of Nepal.

Rashid, A., \&Jehan, Z. (2013). Derivation of quarterly GDP, investment spending, and government expenditure figures from annual data: the case of Pakistan.

Sax, C., \& Steiner, P. (2013).Tempdisagg: Methods for temporal disaggregation and interpolation of time Series, 2013. URL: http://CRAN. R-project.org/package= tempdisagg. R package version 0.22.[p80].

\section{Annex-1}

Table A1. Augmented Dickey Fuller Test Results

\begin{tabular}{|l|c|c|l|}
\hline \multirow{2}{*}{ Variables } & \multicolumn{2}{|c|}{ Level } & \multirow{2}{*}{ Conclusion } \\
\cline { 2 - 3 } & With Intercept & With Intercept and Trend & \\
\hline GDP & 3.439 & 0.763 & Nonstationary \\
\hline TAX & 5.639 & 4.944 & Nonstationary \\
\hline EXPORT & -1.110 & -5.113 & Nonstationary \\
\hline
\end{tabular}

Note: The critical value ofADF test for 'with constant' is -3.00 at $5 \%$ level of significance and it is -

3.60 for 'with intercept and trend'.

Source: Author's Computation

\section{Annex - 2}

Table A2. Engel Granger Co integration Test results

\begin{tabular}{|c|c|c|c|}
\hline \multirow{2}{*}{ Test statistic } & \multicolumn{3}{|c|}{ Critical Value } \\
\cline { 2 - 4 } & 1 Percent Level & 5 Percent Level & 10 Percent Level \\
\hline-2.41 & -2.66 & -1.95 & -1.6 \\
\hline
\end{tabular}

\section{Annex- 3}

Table A3. GDP at current and constant Prices (In million NRs.)

\begin{tabular}{|c|c|c|c|c|c|}
\hline Time & $\begin{array}{c}\text { GDP at } \\
\text { Current Price }\end{array}$ & $\begin{array}{c}\text { GDP at } \\
\text { Constant price } \\
\mathbf{( 2 0 0 0 / 0 1} \text { prices })\end{array}$ & Time & $\begin{array}{c}\text { GDP at } \\
\text { Current Price }\end{array}$ & $\begin{array}{c}\text { GDP } \\
\text { at Constant Price } \\
\mathbf{( 2 0 0 0 / 0 1} \text { prices })\end{array}$ \\
\hline 1998 Q1 & 71596 & 80461 & 2009 Q1 & 212444 & 142017 \\
\hline 1998 Q2 & 76344 & 85308 & 2009 Q2 & 222588 & 157761 \\
\hline 1998 Q3 & 74726 & 83981 & 2009 Q3 & 221088 & 147152 \\
\hline 1998 Q4 & 80391 & 89323 & 2009 Q4 & 253408 & 152866 \\
\hline 1999 Q1 & 82138 & 86461 & 2010 Q1 & 238551 & 143606 \\
\hline 1999 Q2 & 89329 & 95536 & 2010 Q2 & 274111 & 165146 \\
\hline 1999 Q3 & 85583 & 89142 & 2010 Q3 & 272407 & 150522 \\
\hline 1999 Q4 & 87197 & 96351 & 2010 Q4 & 298346 & 157388 \\
\hline 2000 Q1 & 93638 & 95249 & 2011 Q1 & 286540 & 143586 \\
\hline
\end{tabular}




\begin{tabular}{|c|c|c|c|c|c|}
\hline $2000 \mathrm{Q} 2$ & 99178 & 102995 & $2011 \mathrm{Q} 2$ & 318526 & 163716 \\
\hline 2000 Q3 & 93045 & 96824 & $2011 \mathrm{Q} 3$ & 311363 & 149291 \\
\hline $2000 \mathrm{Q} 4$ & 95837 & 99519 & $2011 \mathrm{Q} 4$ & 332053 & 157864 \\
\hline $2001 \mathrm{Q} 1$ & 95336 & 95336 & 2012 Q1 & 318593 & 140138 \\
\hline $2001 \mathrm{Q} 2$ & 104988 & 104988 & $2012 \mathrm{Q} 2$ & 351335 & 164682 \\
\hline $2001 \mathrm{Q} 3$ & 102954 & 102954 & 2012 Q3 & 347015 & 154681 \\
\hline $2001 \mathrm{Q} 4$ & 110151 & 110151 & $2012 \mathrm{Q} 4$ & 370539 & 165324 \\
\hline 2002 Q1 & 106145 & 107126 & $2013 \mathrm{Q1}$ & 354393 & 148824 \\
\hline $2002 \mathrm{Q} 2$ & 110242 & 110940 & $2013 \mathrm{Q} 2$ & 384131 & 166920 \\
\hline $2002 \mathrm{Q} 3$ & 106927 & 103403 & $2013 \mathrm{Q} 3$ & 379740 & 160141 \\
\hline $2002 \mathrm{Q} 4$ & 107083 & 105090 & $2013 \mathrm{Q} 4$ & 406957 & 171156 \\
\hline $2003 \mathrm{Q} 1$ & 102632 & 101939 & $2014 \mathrm{Q} 1$ & 402059 & 162272 \\
\hline $2003 \mathrm{Q} 2$ & 123445 & 121388 & $2014 \mathrm{Q} 2$ & 438797 & 180005 \\
\hline $2003 \mathrm{Q3}$ & 114013 & 109456 & 2014 Q3 & 441664 & 174042 \\
\hline $2003 \mathrm{Q} 4$ & 120236 & 112259 & $2014 \mathrm{Q} 4$ & 476218 & 183741 \\
\hline 2004 Q1 & 111973 & 104971 & $2015 \mathrm{Q} 1$ & 443188 & 171130 \\
\hline $2004 \mathrm{Q} 2$ & 129710 & 122501 & $2015 \mathrm{Q} 2$ & 480516 & 186783 \\
\hline 2004 Q3 & 126262 & 116625 & 2015 Q3 & 478509 & 177112 \\
\hline $2004 \mathrm{Q} 4$ & 132754 & 119128 & $2015 \mathrm{Q} 4$ & 496876 & 182398 \\
\hline 2005 Q1 & 125391 & 114613 & 2016 Q1 & 438005 & 159759 \\
\hline $2005 \mathrm{Q} 2$ & 138259 & 124299 & $2016 \mathrm{Q} 2$ & 513437 & 189459 \\
\hline $2005 \mathrm{Q} 3$ & 130680 & 107375 & $2016 \mathrm{Q} 3$ & 503002 & 183506 \\
\hline $2005 \mathrm{Q} 4$ & 154154 & 130692 & 2016 Q4 & 539116 & 188430 \\
\hline 2006 Q1 & 143933 & 122801 & $2017 \mathrm{Q1}$ & 528654 & 184824 \\
\hline $2006 \mathrm{Q} 2$ & 159010 & 137869 & $2017 \mathrm{Q} 2$ & 595029 & 207935 \\
\hline $2006 \mathrm{Q} 3$ & 148061 & 122377 & $2017 \mathrm{Q} 3$ & 565150 & 196792 \\
\hline $2006 \mathrm{Q} 4$ & 160114 & 126891 & $2017 \mathrm{Q} 4$ & 650650 & 208379 \\
\hline 2007 Q1 & 155096 & 122648 & $2018 \mathrm{Q} 1$ & 576778 & 184751 \\
\hline $2007 \mathrm{Q} 2$ & 168774 & 134627 & $2018 \mathrm{Q} 2$ & 674061 & 215669 \\
\hline 2007 Q3 & 161153 & 126666 & 2018 Q3 & 636774 & 203171 \\
\hline $2007 \mathrm{Q} 4$ & 190836 & 140966 & $2018 \mathrm{Q} 4$ & 738383 & 223332 \\
\hline $2008 \mathrm{Q1}$ & 176697 & 134683 & & & \\
\hline $2008 \mathrm{Q} 2$ & 184924 & 141646 & & & \\
\hline $2008 \mathrm{Q} 3$ & 180853 & 131501 & & & \\
\hline $2008 \mathrm{Q} 4$ & 212783 & 148864 & & & \\
\hline
\end{tabular}

